\title{
Contribuições do geoprocessamento à compreensão do mundo rural e do desmatamento no bioma Amazônia
}

\author{
Evaristo de Miranda ${ }^{1}$ \\ Carlos Alberto de Carvalho ${ }^{2}$ \\ Paulo Roberto Rodrigues Martinho ${ }^{3}$ \\ Osvaldo Tadatomo Oshiro ${ }^{4}$
}

\begin{abstract}
Resumo
O que é um produtor rural na Amazônia? Quantos existem, como e onde vivem? Qual sua relação com o desmatamento? O universo dos produtores rurais e das unidades e áreas de produção amazônicas é complexo e dinâmico. Ele resulta de uma história de milhares de anos. Inclui desde extrativistas de produtos vegetais e animais até os mais modernos agricultores do Brasil (grãos e algodão). Detectar, identificar e mapear sua ocorrência numa grande extensão territorial, onde o hábitat é disperso, a infraestrutura precária e com muitos conflitos fundiários, sempre foi um desafio. $\mathrm{O}$ acesso aos dados do Censo Agropecuário (IBGE) e do Cadastro Ambiental Rural (CAR), em bases geográficas, levaram a Embrapa Territorial a organizar, num bigdata geocodificado, um Sistema de Inteligência Territorial Estratégica do Bioma Amazônia. Mais de um milhão de produtores rurais e unidades e áreas de produção foram identificados e mapeados no bioma, de forma inédita, graças a procedimentos estatístico-matemáticos. Mais de $97 \%$ dos produtores rurais e unidades de produção, em sua maioria pequenos, não participam do processo de desmatamento na Amazônia. Além disso, a análise espaço-temporal geocodificada dos polígonos de desmatamento, entre 2009 e 2018, revelou que 12\% dos casos não ocorrem em áreas rurais e, sim, em áreas protegidas.
\end{abstract}

Palavras-chave: Bioma Amazônia. Produtores rurais. Desmatamento. Geotecnologias. Desenvolvimento regional.

\begin{abstract}
What is a farmer in the Amazon? How many are they, how and where do they live? What is their relationship to deforestation? The universe of farmers and their farmlands in the Amazon is complex and dynamic. It results from a history of thousands of years. It ranges from extractivists of plant and animal products to the most modern farmers in Brazil (grains and cotton). Detecting, identifying and mapping their presence over a large territorial extension, where habitat is dispersed, precarious infrastructure and with many land conflicts, has always been a challenge. The access to data from the Agricultural Census (IBGE) and the Rural Environmental Registry (CAR), on a geographical basis, led Embrapa Territorial to organize, in a geocoded bigdata, a Strategic Territorial Intelligence System of the Amazon Biome. More than one million farmers and their farmlands have been previously identified and mapped in the biome thanks to statistical and mathematical procedures. Over $97 \%$ of farmers and farmlands, mostly small, do not participate in the process of deforestation in the Amazon. In addition, the geocoded spatiotemporal analysis of deforestation polygons between 2009 and 2018 revealed that 12\% of cases do not occur in rural areas but in protected areas.
\end{abstract}

Keywords: Amazon biome. Farmers. Deforestation. Geotechnologies.

\section{Introdução}

O mundo rural na Amazônia é um dos mais complexos, dinâmicos e menos estudados e conhecidos do país. A mais antiga presença humana do Brasil está na Amazônia. São mais de 15.000 anos de antropização, atestados por sítios arqueológicos (geoglifos, florestas de bambus, terras pretas, cerrados antropogênicos etc.) (IPHAN, 2019). Grandes áreas foram ocupadas no

\footnotetext{
${ }^{1}$ Doutor em Ecologia. Pesquisador da Embrapa Territorial. evaristo.miranda@embrapa.br

2 Mestre em Ciência da Computação Analista de TI e geoprocessamento da Embrapa Territorial. carlosalberto.carvalho@embrapa.br

3 Mestre em Agricultura Tropical e Subtropical. Analista de geoprocessamento da Embrapa Territorial. paulo.martinho@embrapa.br

4 Doutor em Engenharia Mecânica. Analista de geoprocessamento da Embrapa Territorial.
} osvaldo.oshiro@embrapa.br 
passado por culturas agrícolas, onde ocorreu - entre outros avanços tecnológicos - a domesticação da mandioca. Esses povos atravessaram milênios e duas eras climáticas. Em seguida veio o povoamento europeu e sucederam-se diversos movimentos migratórios (nordestinos, japoneses, árabes, sulistas etc.), ligados a vários ciclos e momentos econômicos da região e do país. E a dinâmica no uso das terras prossegue, combinando tempo e espaço de forma variada, em toda região.

A complexidade do mundo rural na Amazônia combina, muitas vezes no mesmo local: atividades sem base na terra e ligadas a territórios (apicultura, pesca, caça...); diversos tipos de extrativismos vegetais (palmitos, açaí, castanhas, madeiras, fibras, óleos...); grupos humanos, etnias e comunidades com histórias e origens muito diferentes (indígenas, japoneses, colonos, caboclos, afrodescendentes, sulistas, nordestinos...); unidades e áreas de produção, cuja condição legal é mista e variada (ribeirinhos, proprietários, assentados, ocupantes, extrativistas...). O uso de tecnologias vai desde práticas de baixa produtividade, próximas ao Neolítico, passando por centenas de milhares de pequenos agropecuaristas inseridos na economia local, até os mais modernas sistemas de produção de grãos e algodão, cuja produtividade está entre as maiores do país.

Saber quantos são e onde se encontram os produtores rurais lato sensu e suas complexas unidades e áreas de produção da Amazônia não é fácil. Além dessa diversidade produtiva, há ainda a grande extensão territorial, o hábitat disperso, a infraestrutura precária, as incertezas geradas por conflitos agrários, a mobilidade territorial de parte da população e a incipiente regularização fundiária a desafiar a capacidade de análise das instituições e atores do desenvolvimento regional.

Esta pesquisa buscou ampliar a compreensão atual do mundo rural amazônico através de um estudo circunstanciado e quantificado, em bases territoriais, dos produtores rurais lato sensu, em particular dos pequenos agricultores, em cada estado da região. Foram desenvolvidos métodos e procedimentos inéditos, apoiados em geoprocessamento, para valorizar as novas bases de dados do Censo Agropecuário do IBGE (2017) e do Cadastro Ambiental Rural (2019).

Para contribuir para uma melhor compreensão do mundo rural na Amazônia, em bases quantificadas e territoriais, este estudo teve como objetivos identificar, qualificar e quantificar o universo atual dos produtores rurais lato sensu e suas unidades de produção no bioma Amazônia, em bases territoriais e analisar em bases numéricas e cartográficas a participação efetiva do mundo rural nos processos de desmatamento no bioma Amazônia.

\section{Material e métodos}

\subsection{Recorte geográfico}

Entre as razões de equívocos e desinformação sobre o mundo rural amazônico estão análises e interpretações realizadas com referências geográficas distintas, às vezes utilizadas e confrontadas de forma abusiva. Bacia Amazônica (3.844.877 km2), Amazônia Legal (5.217.423 km2), Bioma Amazônia (4.199.249 km2) e Região Norte (3.853.677 km2) são recortes geográficos que se recobrem e não coincidem. A escolha de um determinado recorte territorial para 
representar a Amazônia e seu mundo rural nunca é neutra, sempre apresenta vantagens e inconvenientes. Esta pesquisa teve por base o recorte do bioma Amazônia.

Os biomas são a base de políticas públicas de desenvolvimento regional, crédito, meio ambiente etc. O bioma Amazônia é abrangente e preciso na delimitação dos ecossistemas associados às florestas equatoriais e à história da presença humana na Amazônia (MIRANDA, 2007). Recobrindo 49,3\% do país, o bioma Amazônia engloba a totalidade dos estados do Acre, Amapá, Amazonas, Pará, Rondônia, Roraima e parte do Mato Grosso, Maranhão e Tocantins (Fig. 1).

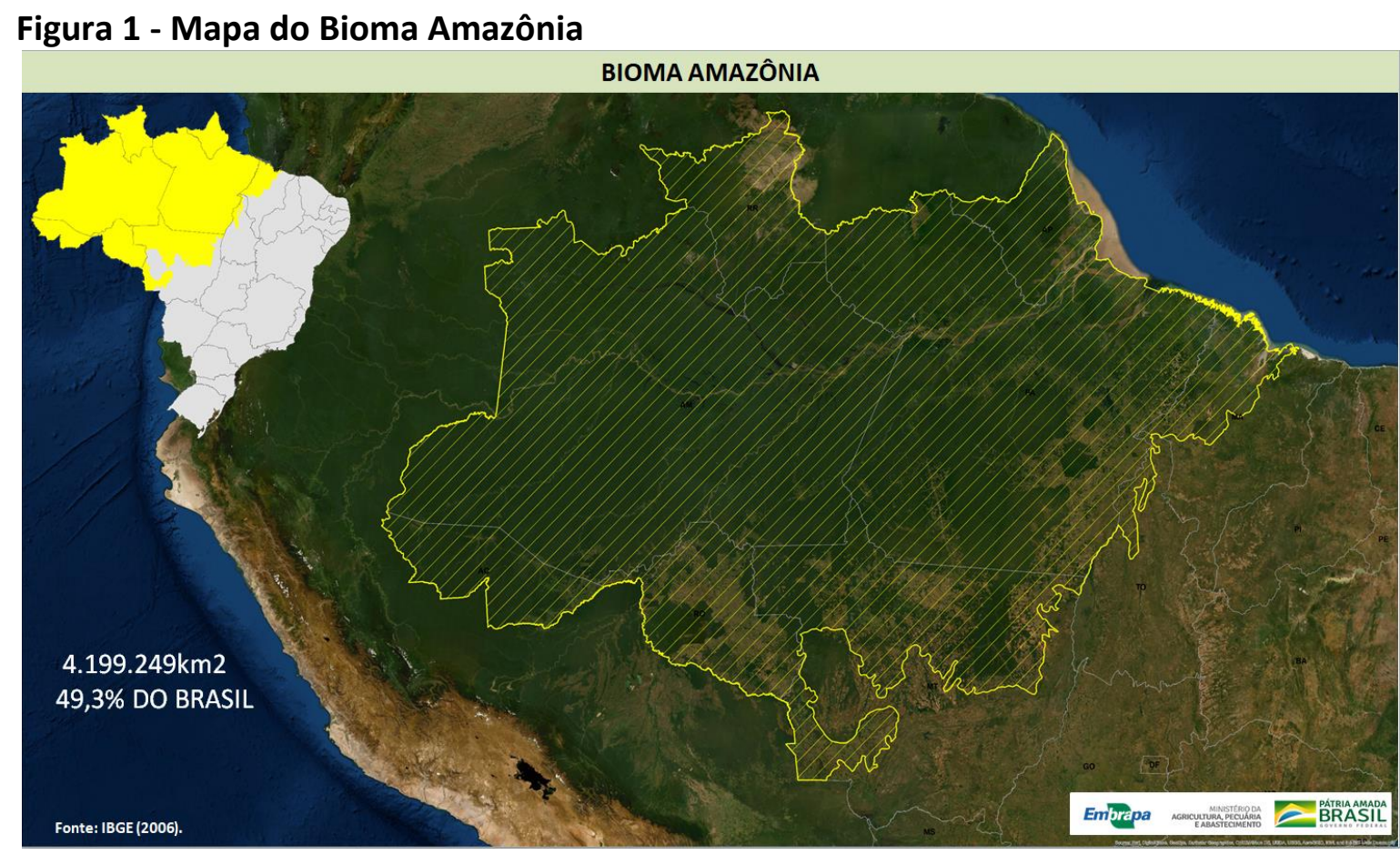

Fonte: IBGE (2019d).

\subsection{Bases cartográficas}

Para realização desta pesquisa foi estruturado um sistema de informações geográficas geocodificadas intitulado Sistema de Inteligência Territorial Estratégica do Bioma Amazônia (SITE Amazônia) (MIRANDA et al., 2019). Ele é a integração de softwares, ferramentas e técnicas com acervos de dados numéricos, iconográficos e cartográficos, em sistemas de informações geográficas, apoiados em bancos de dados espaciais. O SITE Amazônia é capaz de gerar análises espaciais (sobreposições, cálculos de áreas, união de feições etc.) e produzir resultados no formato de mapas, apresentações e relatórios. Nos formatos e sistemas de projeções geográficas (INPE, 2011), o SITE Amazônia atende às normativas do Instituto Brasileiro de Geografia e Estatística (IBGE, 2019a) e da Infraestrutura Nacional de Dados Espaciais (INDE, 2019). 


\subsection{Equipamentos, sistemas computacionais e programas}

Os sistemas computacionais utilizados na construção do SITE Amazônia e neste estudo apoiaram-se em equipamentos de informática com grande capacidade de armazenamento e de desempenho: 5 Estações HP Intel Core i7 de 3.4GHz com 16GB de RAM, HD SSD de 500 GB e HD de 2 TB; 1 Servidor Blade SY480Gen10 com processadores Intel Xeon Silver de 10 núcleos, 192 GB de Memória RAM e 2 HDs de 600GB e um sistema de armazenamento de dados de grande capacidade Storage HP MSA-2050 com capacidade de 192TB.

O principal programa utilizado na construção do SITE Amazônia foi o ArcGIS, em função de sua capacidade de lidar com grandes bases de dados espaciais e de seus módulos específicos de análise espacial. As operações com dados tabulares foram realizadas com o Microsoft Excel e suas funções internas. Os softwares utilizados foram: ESRI ArcGIS for Desktop 10.7 com módulos spatial analyst e geostatistical (ESRI, 2019a); Google Earth Pro (GOOGLE, 2019); Sistema de File Geodatabase suportado pelo ArcGIS 10.7 (ESRI, 2019b) e o Pacote Office com Microsoft Excel para funções estatísticas.

\subsection{Limites políticos, de bioma e de atribuição legal das terras}

Os limites dos municípios e estados foram obtidos das divisões territoriais do IBGE em arquivo digital shapefile (IBGE, 2014). Os do bioma Amazônia são os oficiais do Ministério do Meio Ambiente, recortados do shapefile dos biomas do Brasil. Os limites geocodificados das Unidades de Conservação, Terras Indígenas, Áreas Militares, Assentamentos Agrários e Comunidades Quilombolas foram obtidos junto à INDE, recortados e estruturados digitalmente, com os ajustes de projeção e nomenclatura no sistema de referência SIRGAS 2000 (IBGE, 2010), com a projeção adotada pelo IBGE (IBGE, 2014) nos cálculos de áreas.

\subsection{Dados geocodificados dos imóveis rurais do CAR}

Com o Código Florestal de 2012, o CAR (SFB, 2019) se tornou um registro eletrônico obrigatório para todos os imóveis rurais. Seu certificado não trata da condição jurídica ou fundiária da imóvel. Segundo o Código Florestal (Lei no 12.651, de 25 de maio de 2012) em seu Capítulo VI, Art. 29, § 20: "O cadastramento não será considerado título para fins de reconhecimento do direito de propriedade ou posse...". No cadastro, além da identificação e caracterização alfanumérica, os produtores delimitaram seus imóveis rurais sobre imagens de satélite com 5 metros de resolução espacial (Fig. 2), oferecidas pelo Serviço Florestal Brasileiro (SFB). 
Figura 2 - Perímetro de um imóvel rural com polígonos delimitando áreas de vegetação nativa, nascentes e cursos d'água no cadastro do CAR

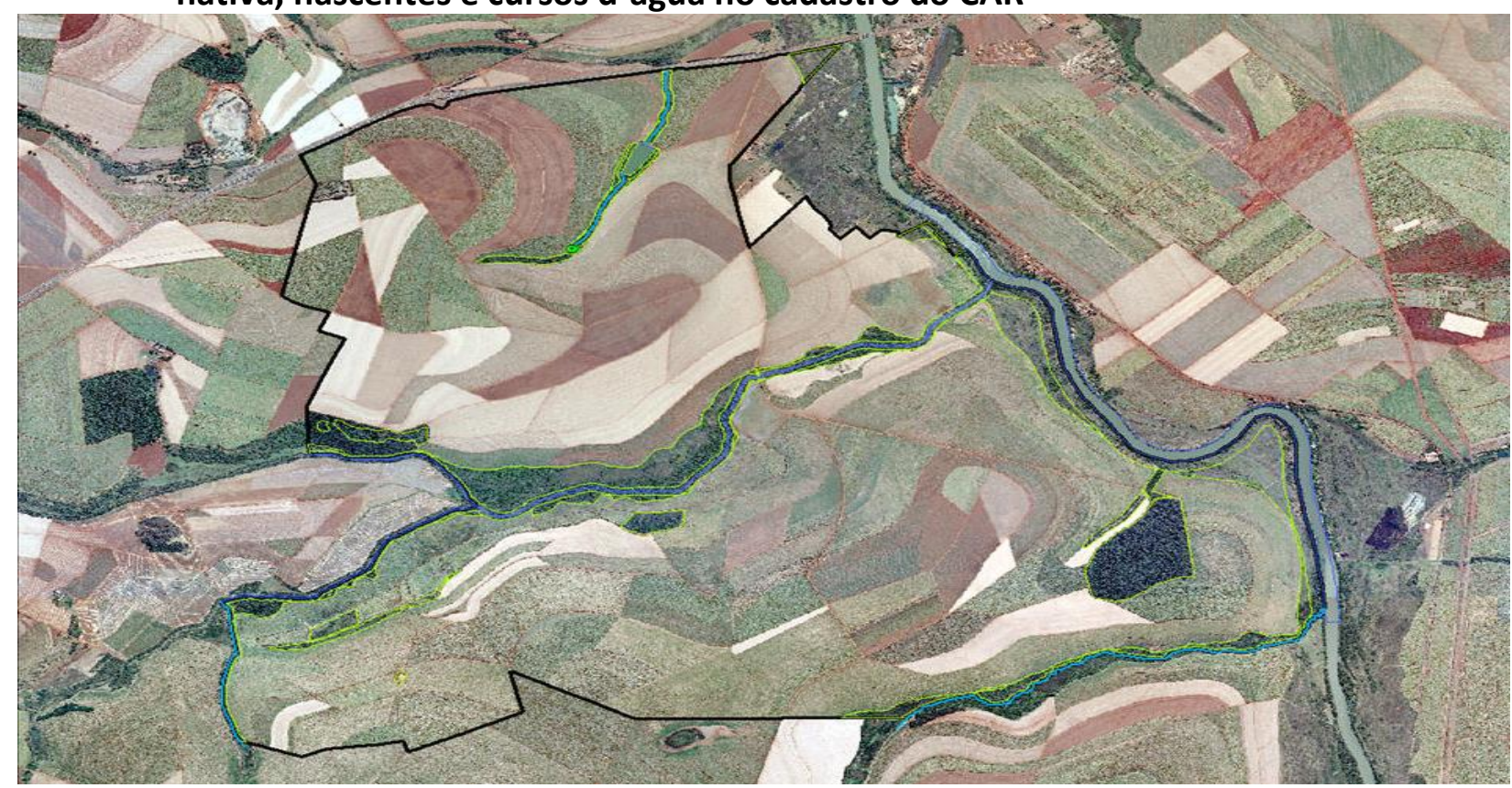

Fonte: Serviço Florestal Brasileiro - SFB (2019)

Feito o download dos dados dos imóveis rurais do CAR no SITE Amazônia, os dados geocodificados foram consultados e trabalhados de forma hierarquizada por bioma, estado, município e, até, em cada imóvel rural isoladamente. Em nível de Estado, a figura 3 ilustra o exemplo da repartição territorial de 116.118 imóveis rurais cadastrados no CAR do estado de Rondônia.

Figura 3 - Limites dos imóveis rurais (polígonos) no Estado de Rondônia

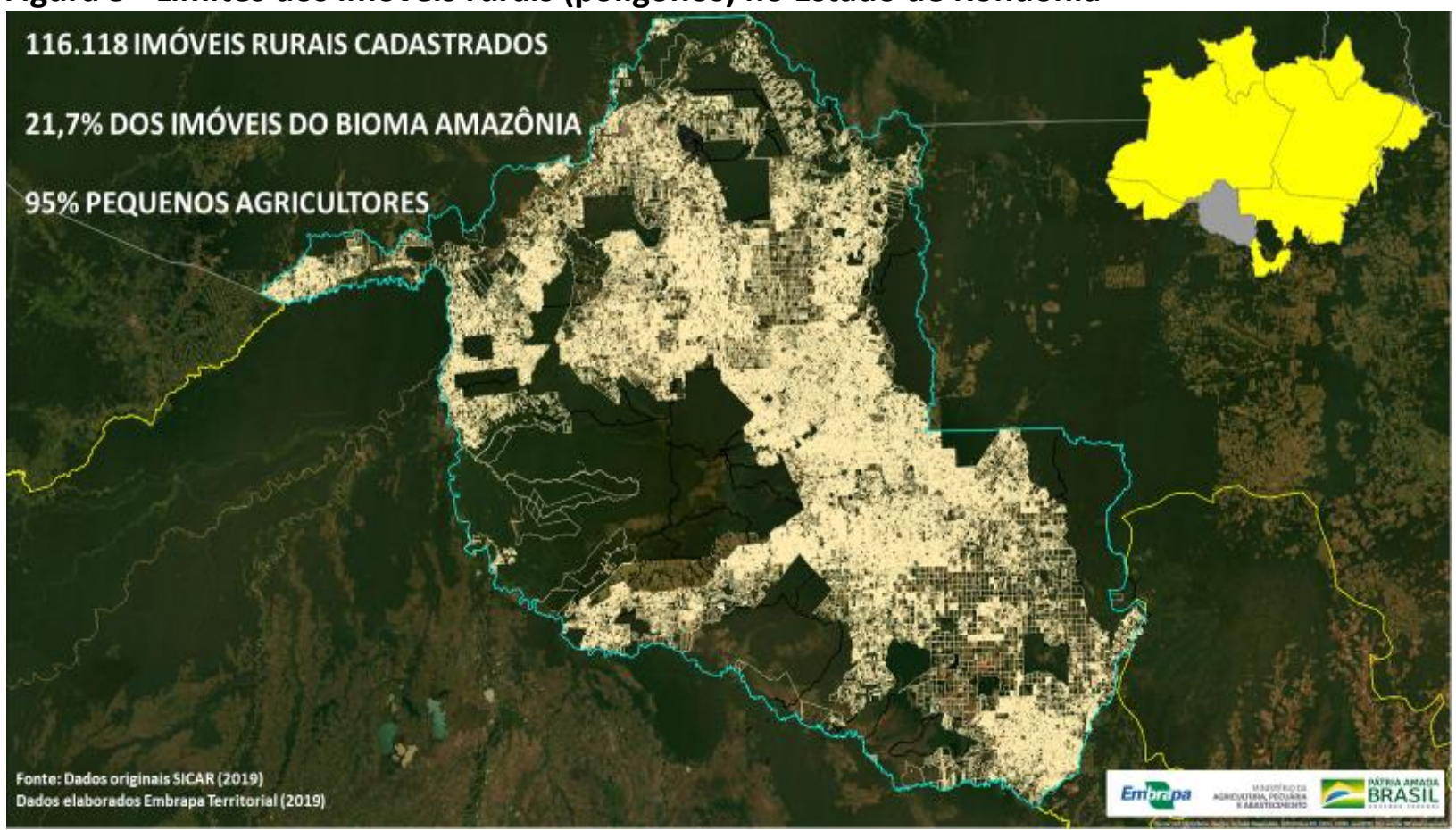

Fonte: SFB (2019). 
Em escala municipal, a figura 4 ilustra a repartição territorial de 3.468 imóveis rurais cadastrados no CAR no município de Machadinho d’Oeste em Rondônia.

Figura 4 - Exemplo dos imóveis rurais (polígonos) no município de Machadinho d’Oeste - RO

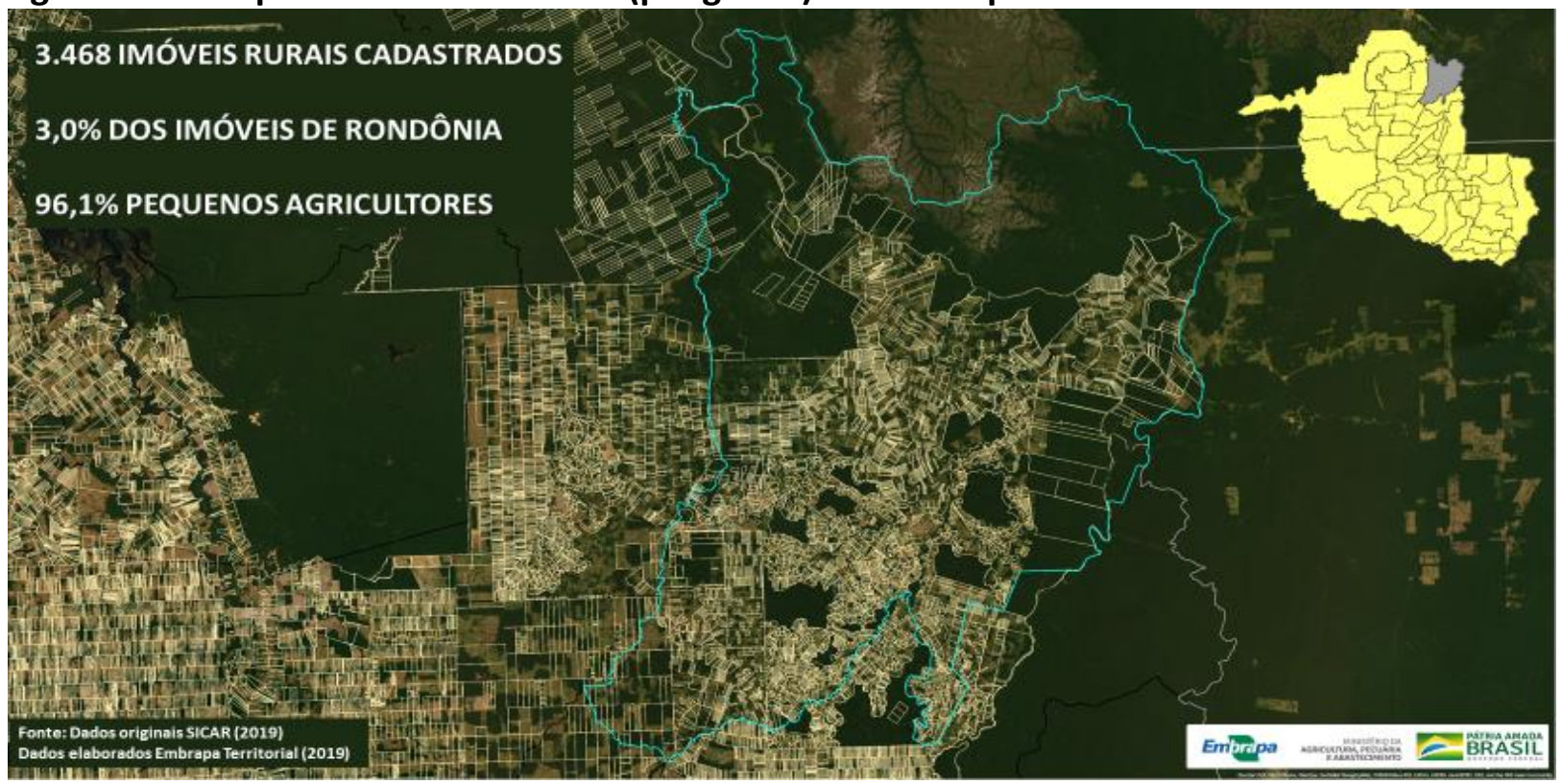

Fonte: SFB (2019).

Em escala local, a figura 5 ilustra os limites e detalhes internos do uso em parte dos imóveis rurais do CAR no município de Machadinho d'Oeste em Rondônia.

\section{Figura 5 - Limites de imóveis rurais (polígonos) em Machadinho D’Oeste/RO}

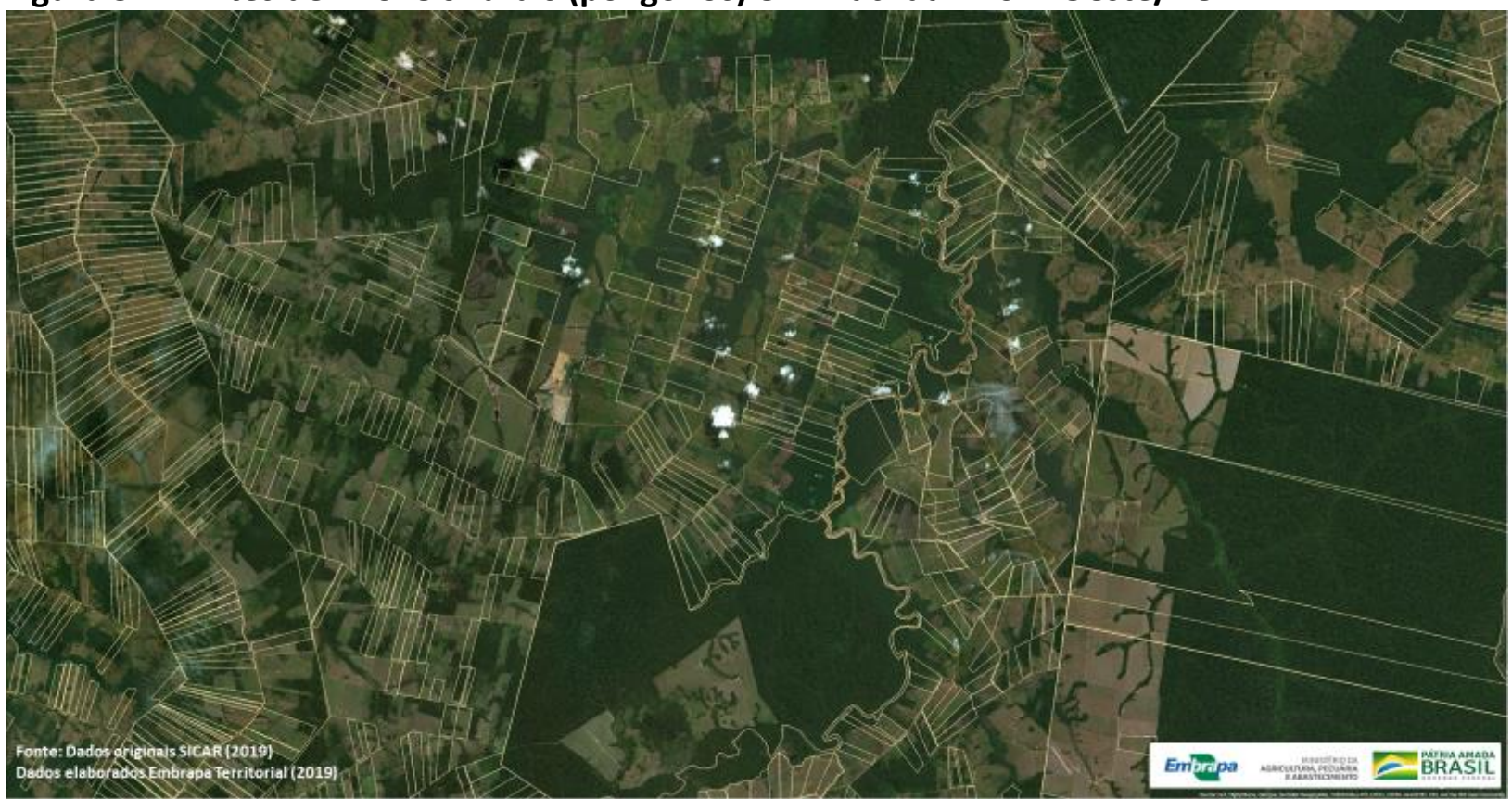

Fonte: SFB (2019). 
2.6 Dados geocodificados dos estabelecimentos agropecuário do IBGE

O Censo Agropecuário faz o levantamento dos estabelecimentos agropecuários do Brasil e das atividades agropecuárias neles desenvolvidas (IBGE, 2019a). Em 2017, registrou os endereços coletados e as coordenadas geográficas digitais de cada estabelecimento agropecuário e as organizou no Cadastro Nacional de Endereços para Fins Estatísticos (CNEFE). A partir do CNEFE, a Embrapa Territorial realizou o download (IBGE, 2019b), por Estado da Federação, das planilhas com as coordenadas dos estabelecimentos agropecuários levantados no Censo Agropecuário 2017.

Utilizando técnicas de geoprocessamento, as coordenadas geográficas dessas planilhas foram convertidas em um banco de dados espacial. Seguiu-se a realização do recorte espacial do bioma Amazônia sobre essa base espacial de estabelecimentos, resultando num total de mais de 677.000 estabelecimentos cadastrados no bioma Amazônia. Essas geolocalizações foram organizadas em nível de estado e município. Em escala local, a figura 6 ilustra a repartição territorial dos estabelecimentos agropecuários em Machadinho d’Oeste em Rondônia.

Figura 6 - Repartição territorial dos estabelecimentos agropecuários do IBGE e o trajeto dos recenseadores em Machadinho d'Oeste - RO

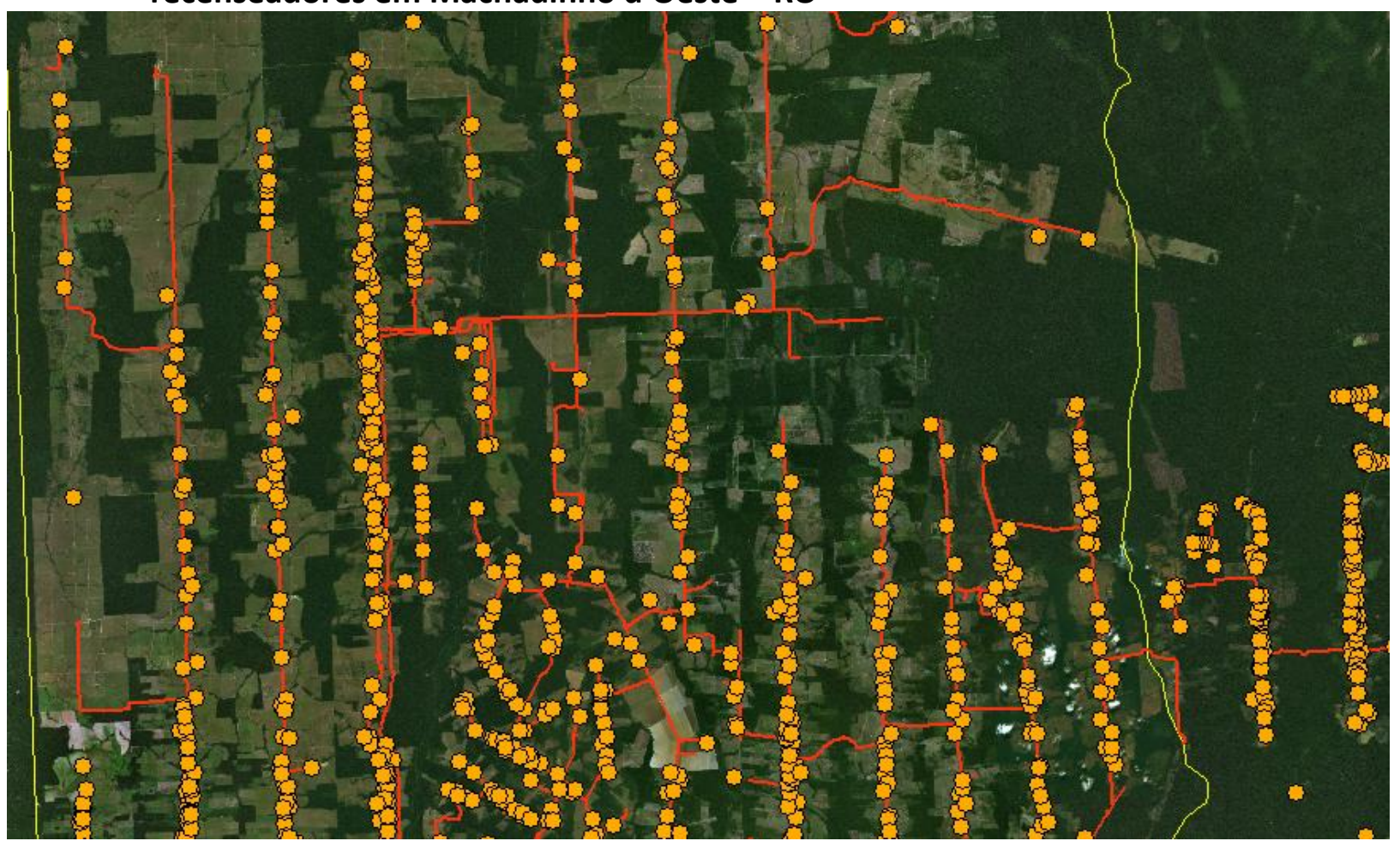

Fonte: IBGE (2019b).

\subsection{Dados geocodificados do desmatamento do Projeto PRODES}

O desmatamento no bioma Amazônia, por corte raso, é monitorado desde 1988 pelo projeto PRODES do INPE (INPE, 2019). As taxas anuais são estimadas a partir dos incrementos de desmatamento identificados em imagens dos satélites LANDSAT (20 a 30 metros de resolução espacial e revisita de 16 dias). A área mínima mapeada pelo PRODES é de 6,25 hectares. A área 
recoberta pelo PRODES (Fig. 7) não corresponde nem à totalidade da Amazônia Legal, nem à bacia Amazônica, nem ao bioma Amazônia, nem à Região Norte. O projeto, na realidade, monitora 89\% da área do bioma Amazônia e 76,4\% da Amazônia Legal.

Figura 7 - Área de estudo do Projeto PRODES

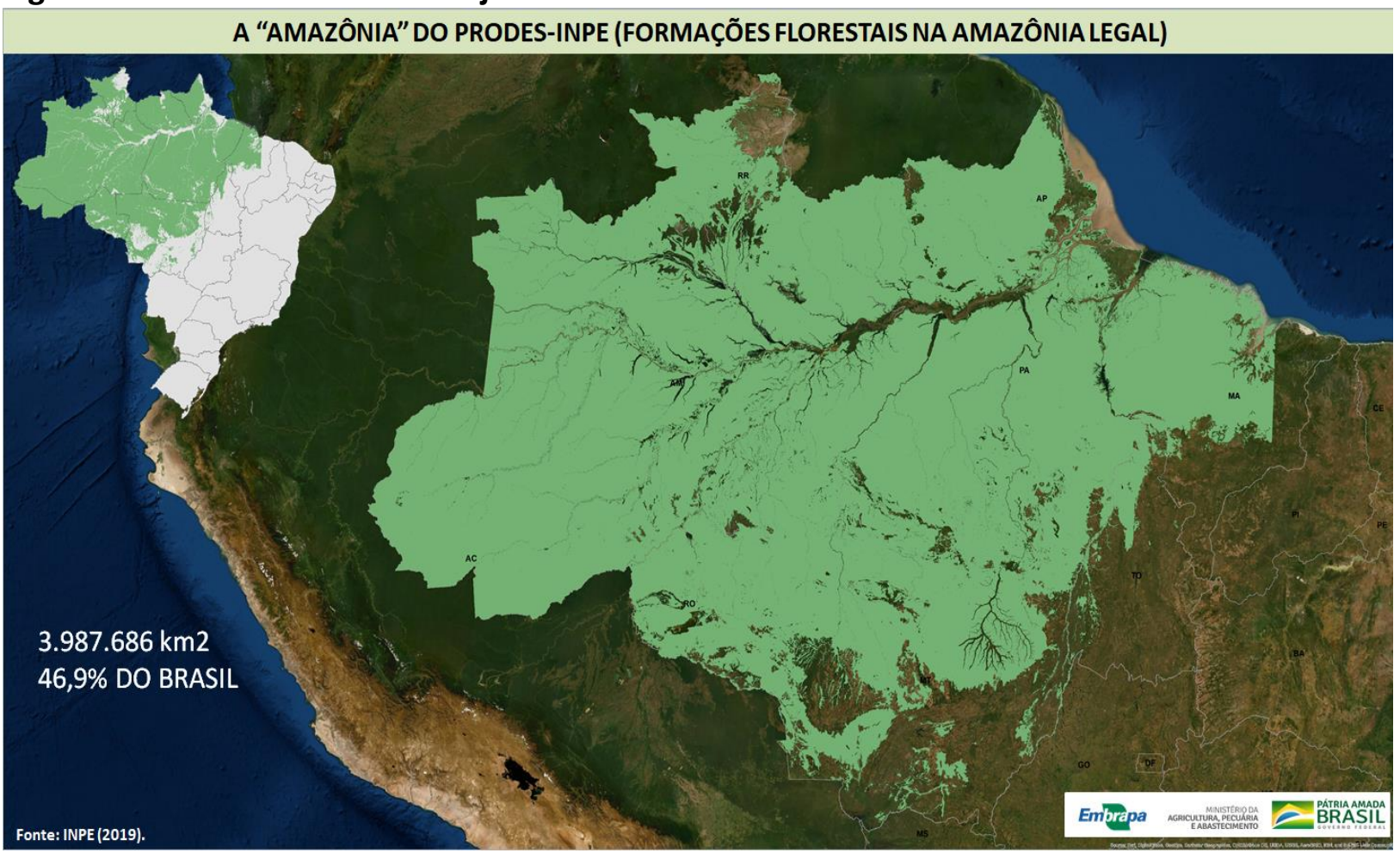

Fonte:INPE (2019).

A abrangência geográfica inicial do PRODES foi definida por uma interpretação das formações florestais na Amazônia Legal, incluindo partes do Pantanal e grandes porções do Cerrado até a vizinhança do estado de Goiás. Essa realidade nem sempre é considerada em análises do desmatamento e reitera a necessária clareza dos recortes territoriais sobre os quais se projetam números e análises.

Do website do Projeto PRODES foram baixados todos os arquivos shapefiles dos polígonos dos desmatamentos de 2009 a 2018 e incorporados ao SITE Amazônia, para quantificar número e tamanho dos polígonos, caracterizar sua repartição territorial e temporal e sua ocorrência em diferentes atribuições das terras (imóveis rurais, unidades de conservação, terras indígenas, assentamentos etc.). 


\section{Resultados}

\section{I - O UNIVERSO DOS PRODUTORES RURAIS NO BIOMA AMAZÔNIA}

I.1 Quantificação dos imóveis rurais do CAR

Até abril de 2019, no bioma Amazônia, registraram-se no CAR mais de 534.261 imóveis rurais. A equipe integrou essas informações no SITE Amazônia e procedeu a diversos cálculos. A Tabela 1 apresenta os números obtidos nos estados.

Tabela 1 - Repartição dos imóveis rurais do CAR nos estados do bioma Amazônia

\begin{tabular}{r|rrr}
\hline \multicolumn{1}{c}{$\begin{array}{c}\text { Estados no Bioma } \\
\text { Amazônia }\end{array}$} & $\begin{array}{c}\text { Número de imóveis rurais } \\
\text { no Bioma Amazônia }\end{array}$ & $\begin{array}{c}\text { \% em relação ao número de } \\
\text { imóveis rurais no Bioma Amazônia }\end{array}$ & \% acumulada \\
\hline PONDÔNIA & 205.422 & 38,4 & 38,4 \\
MATO GROSSO & 116.118 & 21,7 & 60,2 \\
AMAZONAS & 81.286 & 15,2 & 75,4 \\
ACRE & 48.644 & 9,1 & 84,5 \\
MARANHÃO & 35.036 & 6,6 & 91,1 \\
RORAIMA & 25.795 & 4,8 & 95,9 \\
TOCANTINS & 8.927 & 1,7 & 97,6 \\
AMAPÁ & 7.590 & 1,4 & 99,0 \\
TOTAL & 5.443 & 1 & 100,0 \\
\hline
\end{tabular}

Fonte: SFB (2019).

A Figura 8 fornece uma representação sintética da repartição territorial dos 534.261 imóveis rurais do bioma Amazônia, registrados no CAR.

Figura 8 - Visão sintética da repartição territorial dos imóveis rurais do CAR no bioma Amazônia

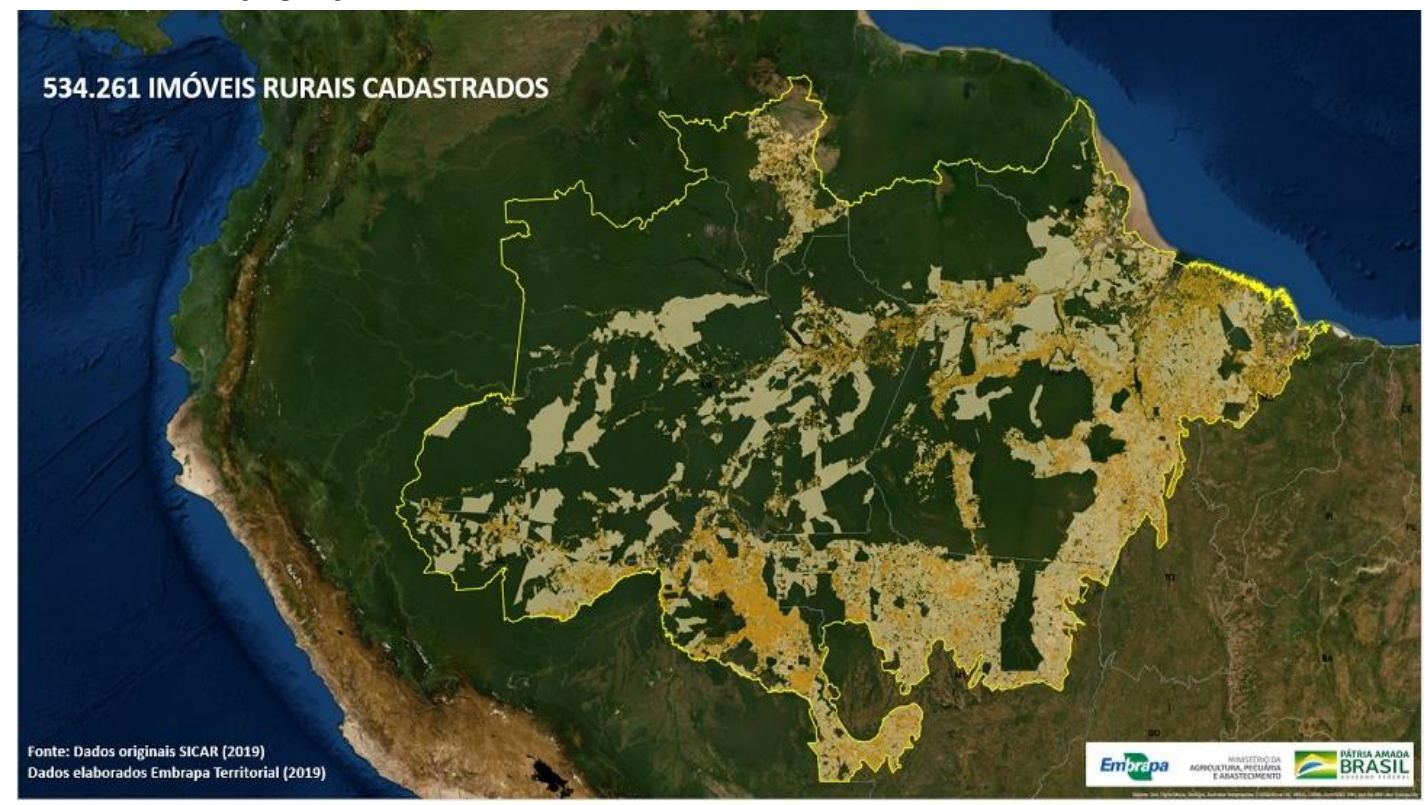

Fonte: SFB (2019). 
Os estados do Pará, Rondônia e Mato Grosso reúnem 75\% dos imóveis rurais cadastrados no CAR. Já Roraima, Tocantins e Amapá reúnem apenas 4\%. Cada um dos 534.261 imóveis rurais foi identificado e cadastrado no SITE Amazônia.

I.2 Quantificação dos Estabelecimentos Agropecuários do IBGE

A equipe da Embrapa Territorial integrou as coordenadas geográficas de cada um dos 677.596 estabelecimentos agropecuários do Censo Agropecuário de 2017 no SITE Amazônia. Várias análises numéricas, gráficas e cartográficas foram realizadas. A Tabela 2 apresenta os números obtidos da repartição territorial dos estabelecimentos agropecuários nos estados do bioma Amazônia.

Tabela 2 - Estabelecimentos agropecuários nos estados do bioma Amazônia

\begin{tabular}{l|rrr}
\hline $\begin{array}{l}\text { ESTADOS NO BIOMA } \\
\text { AMAZÔNIA }\end{array}$ & $\begin{array}{c}\text { NÚMERO DE } \\
\text { ESTABELECIMENTOS } \\
\text { AGROPECUÁRIOS DO } \\
\text { CENSO 2017 NO BIOMA } \\
\text { AMAZÔNIA }\end{array}$ & $\begin{array}{c}\text { \% EM RELAÇÃO AO NÚMERO DE } \\
\text { ESTABELECIMENTOS } \\
\text { AGROPECUÁRIOS DO CENSO 2017 } \\
\text { NO BIOMA AMAZÔNIA }\end{array}$ & \% ACUMULADA \\
\hline PARÁ & 281.718 & 41,6 & 41,6 \\
RONDÔNIA & 91.440 & 13,5 & 55,1 \\
MARANHÃO & 82.700 & 12,2 & 67,3 \\
AMAZONAS & 80.923 & 11,9 & 79,2 \\
MATO GROSSO & 67.522 & 10,0 & 89,2 \\
ACRE & 37.352 & 5,5 & 94,7 \\
RORAIMA & 16.848 & 2,5 & 97,2 \\
TOCANTINS & 10.586 & 1,6 & 98,7 \\
AMAPÁ & 8.507 & 1,3 & 100,0 \\
\hline \multicolumn{1}{c}{ TOTAL } & $\mathbf{6 7 7 . 5 9 6}$ & $\mathbf{1 0 0 , 0}$ & \\
\hline
\end{tabular}

Fonte: IBGE (2019a).

A Figura 9 oferece uma visão sintética da localização e da repartição territorial dos 677.596 estabelecimentos agropecuários levantados pelo IBGE em 2017. 
Figura 9 - Visão sintética da repartição territorial dos estabelecimentos agropecuários recenseados pelo IBGE no bioma Amazônia

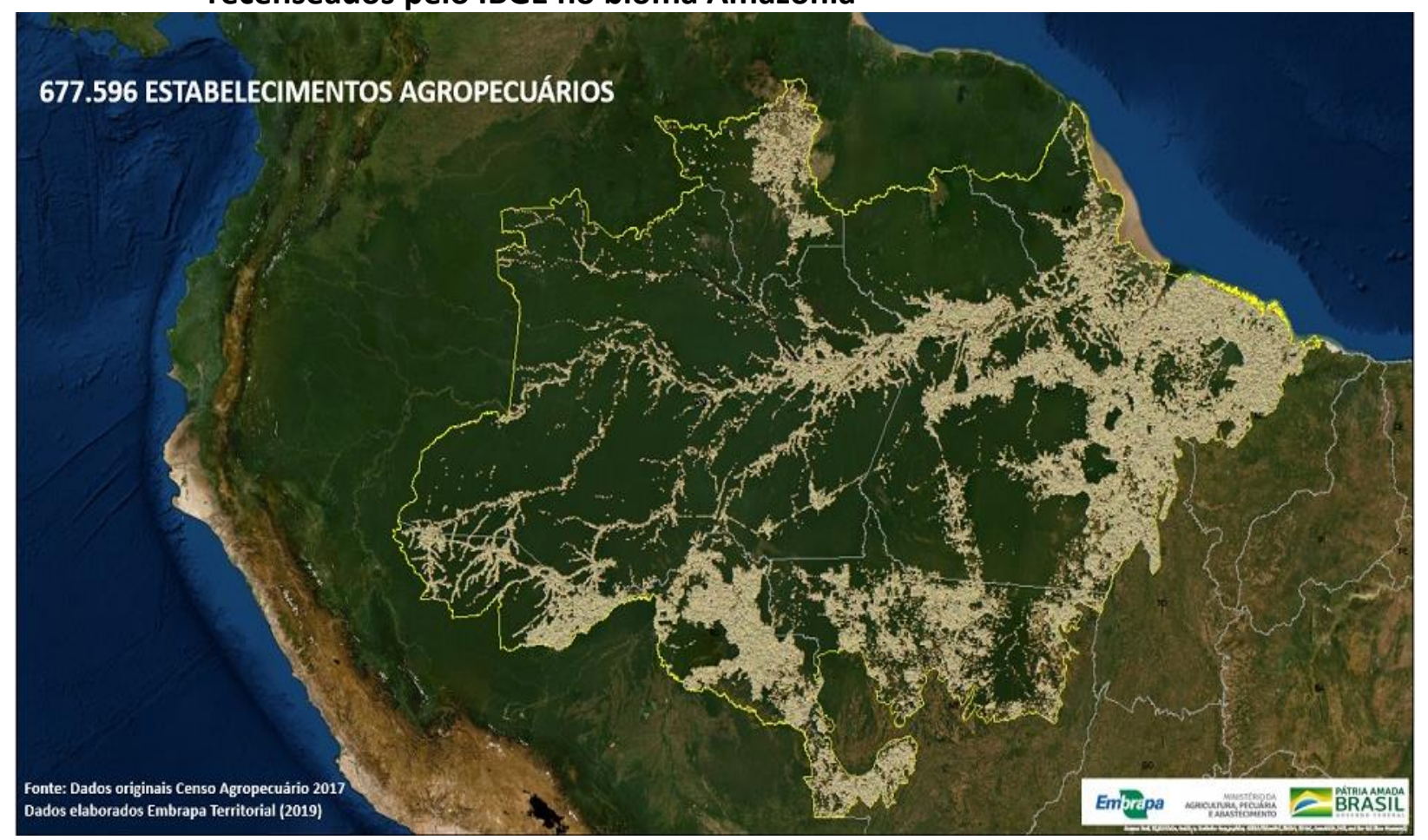

Fonte: IBGE (2019).

A concentração é maior nos estados do Pará e de Rondônia. Para atingir mais de $75 \%$ dos estabelecimentos agropecuários do bioma Amazônia (79,2\%) é necessário agregar os dados dos estados do Maranhão e Amazonas. Já Roraima, Tocantins e Amapá reúnem apenas 5\% do total.

\section{I.3 Quantificação integrada dos produtores rurais}

O bigdata de informações cartográficas e numéricas sobre produtores rurais e unidades de produção do IBGE (2017) e do CAR (2019) no bioma Amazônia, totalizou mais de um milhão de registros (MIRANDA et al., 2017). O tratamento geocodificado unificou e quantificou produtores rurais, unidades e áreas de produção de duas abordagens institucionais e conceituais diferentes.

O tratamento quantitativo considerou que um imóvel rural do CAR pode comportar mais de um estabelecimento agropecuário em seu interior e vice-versa. Por exemplo, hipoteticamente, em um único imóvel rural podem existir cinco estabelecimentos agropecuários: uma parte do imóvel rural pode estar alocada a uma família de meeiros; outra a um arrendatário; outra a um parceiro; outra pode estar invadida por ocupantes e outra, ainda, explorada pelo proprietário.

Já, um grande estabelecimento agropecuário, equivalente a um registro no IBGE, pode dar lugar a vários CARs, em número idêntico ao dos CCIRs que o compõe. Na prática, grandes estabelecimentos agropecuários, como usinas de cana-de-açúcar ou empresas de reflorestamento ou de pecuária, dão origem a vários CARs, um para cada Certificado de Cadastro de Imóvel Rural (CCIR). 
Em São Paulo, por exemplo, com um dos melhores cadastros fundiários do país, o IBGE registrou em 2017 cerca de 188.000 estabelecimentos agropecuários enquanto que no CAR existem cerca de 347.000 imóveis rurais devidamente registrados, com seus limites geocodificados. Uma diferença de 159.000 registros. O fenômeno é análogo em todos os estados do Sul.

Essas e outras considerações conceituais sobre a unidade econômica básica na agricultura foram transformadas em regras matemáticas para tratar os dados geocodificados no SITE Amazônia (NEUMANN; VIVIEN, 2019). Os cálculos evidenciaram a existência de três subpopulações de produtores rurais: a dos estabelecimentos agropecuários do IBGE coincidentes territorialmente com os imóveis rurais do CAR e as dos estabelecimentos agropecuários do IBGE não correspondentes aos imóveis rurais cadastrados no CAR e vice-versa.

Tabela 4 - Repartição do total de produtores rurais por estado no bioma Amazônia

\begin{tabular}{l|rrr}
\hline \multicolumn{1}{l}{ ESTADOS NO BIOMA } & $\begin{array}{r}\text { TOTAL DE PRODUTORES RURAIS E/OU } \\
\text { UNIDAOONNIA }\end{array}$ & $\%$ & \% ACUMULADA \\
\hline PARÁ & 407.341 & 40,4 & 40,4 \\
RONDÔNIA & 157.705 & 15,6 & 56,1 \\
AMAZONAS & 118.604 & 11,8 & 67,8 \\
MATO GROSSO & 113.333 & 11,2 & 79,1 \\
MARANHÃO & 100.738 & 10,0 & 89,1 \\
ACRE & 57.674 & 5,7 & 94,8 \\
RORAIMA & 23.750 & 2,4 & 97,2 \\
TOCANTINS & 15.455 & 1,5 & 98,7 \\
AMAPÁ & 13.124 & 1,3 & 100,0 \\
& $\mathbf{1 . 0 0 7 . 7 2 4}$ & $\mathbf{1 0 0}$ & \\
\hline
\end{tabular}

Fonte: IBGE (2019a).

A união, em bases geocodificadas, dessas subpopulações, revelou a existência de mais de 1.000.000 localizações ou situações de produtores rurais, unidades e áreas de produção. Cada uma está referenciada geograficamente. Desse conjunto, mais de $89 \%$ são pequenos, com áreas inferiores a quatro módulos fiscais (Tab. 4). A concentração da repartição territorial (imóveis rurais e estabelecimentos agropecuários) é maior no Pará, Rondônia, Amazonas e Mato Grosso (79\%).

\section{II - O MUNDO RURAL E O DESMATAMENTO NO BIOMA AMAZÔNIA}

Qual a participação desse universo de produtores rurais e unidades de produção no processo de desmatamento no bioma Amazônia? A análise inicial baseou-se nos resultados de 2018 do PRODES. Definidos procedimentos geocodificados e indicadores, analisou-se a dinâmica do desmatamento nos últimos 10 anos.

II.1 Áreas desmatadas no bioma Amazônia em 2018

As áreas desmatadas totalizaram $7.037 \mathrm{~km} 2$ ou 703.732 ha (Tab. 5) em 2018. Pará, Mato Grosso e Rondônia concentraram 75\% dos desmatamentos. 
Tabela 5 - Áreas desmatadas no bioma Amazônia entre 2017 e 2018 (PRODES)

\begin{tabular}{l|rrr}
\hline ESTADOS & ÁREA DESMATADA (HA) & $\%$ & \% ACUMULADA \\
\hline PARÁ & 267.087 & 38,0 & 38,0 \\
MATO GROSSO & 136.336 & 19,4 & 57,3 \\
RONDÔNIA & 122.523 & 17,4 & 74,7 \\
AMAZONAS & 106.260 & 15,1 & 89,8 \\
ACRE & 46.135 & 6,6 & 96,4 \\
RORAIMA & 13.004 & 1,8 & 98,2 \\
MARANHÃO & 9.301 & 1,3 & 99,6 \\
AMAPÁ & 2.454 & 0,3 & 99,9 \\
TOCANTINS & 631 & 0,1 & 100,0 \\
TOTAL & $\mathbf{7 0 3 . 7 3 2}$ & $\mathbf{1 0 0 , 0}$ & \\
\hline
\end{tabular}

Fonte: INPE (2019).

A figura 10 ilustra a repartição territorial dos polígonos desmatados em 2018. As manchas das áreas desmatadas foram amplificadas para que sejam visíveis.

Figura 10 - Repartição territorial das áreas desmatadas no bioma Amazônia entre 2017 e 2018, segundo dados do Projeto PRODES

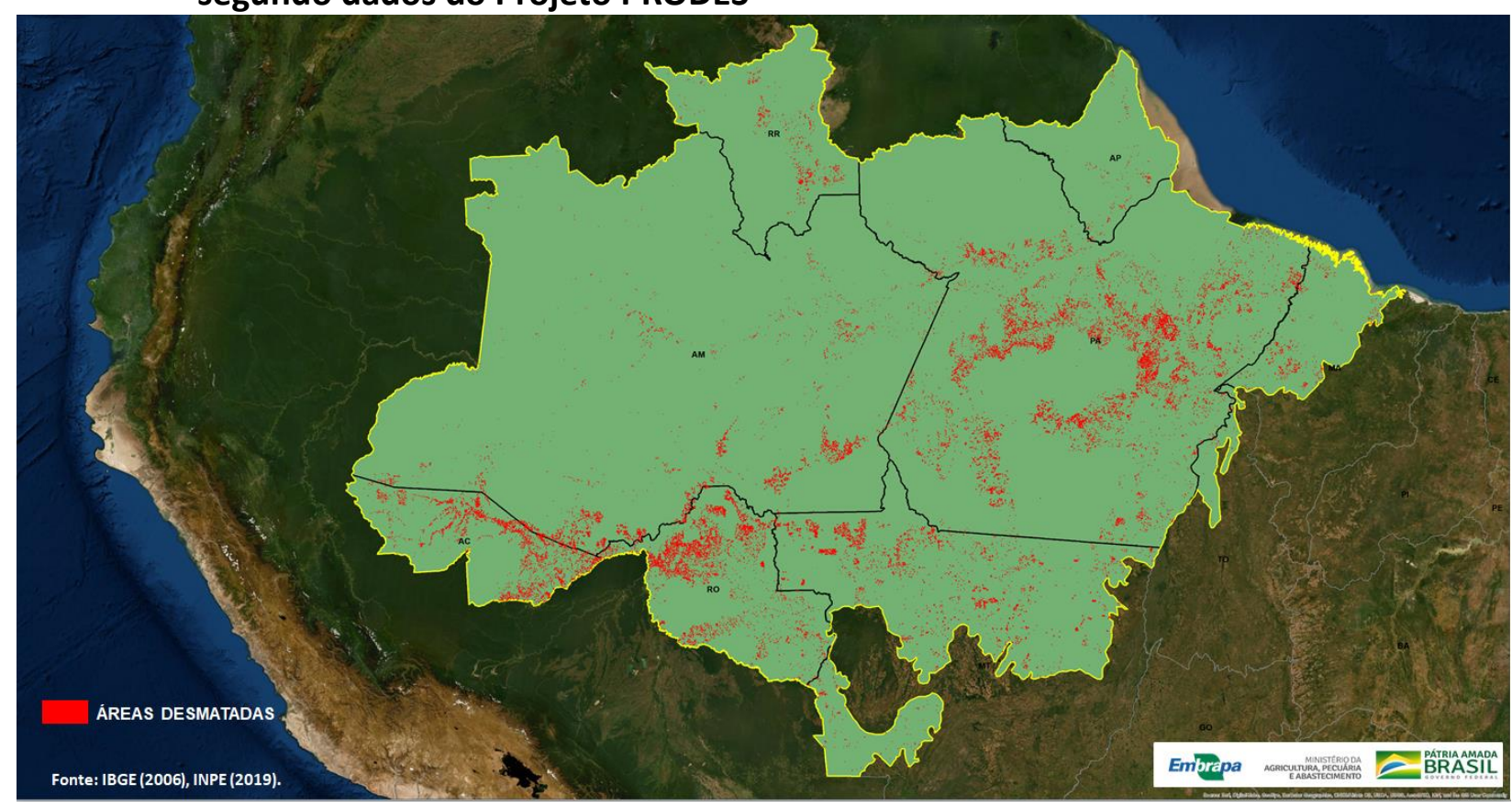

Fonte: INPE (2019).

II.2 A distribuição dos tamanhos dos desmatamentos

O tratamento geocodificado dos polígonos quantificou que a área total desmatada, entre 2017 e 2018, no bioma Amazônia resultou da soma de 32.658 polígonos (desmatamentos individuais) mapeados. A média dos desmatamentos foi de 21,5 ha (desvio padrão de 66,2 ha) enquanto a mediana foi de 10,6 ha. Esses três parâmetros ilustram a grande assimetria dessa distribuição. O valor mínimo da série foi de 6,3 ha, associado à capacidade de deteç̧ão do satélite. 
A análise das 32.658 áreas desmatadas em função do tamanho indicou uma forte concentração de polígonos de pequenas áreas (92\% das áreas são inferiores a 40 ha) e um número pequeno de polígonos com grandes áreas desmatadas.

II.3 Os desmatamentos nas classes de atribuição legal das terras

Uma primeira aproximação da participação do mundo rural nos processos de desmatamentos foi obtida pelo tratamento geocodificado da ocorrência das áreas e do número de polígonos nas classes de atribuição das terras no bioma (Tab. 6).

Tabela 6 - Áreas desmatadas no mundo rural e em áreas protegidas no bioma Amazônia em 2018

\begin{tabular}{|c|c|c|}
\hline Categoria & Área em ha & $\%$ do Desmatamento \\
\hline \multicolumn{3}{|l|}{ MUNDO RURAL } \\
\hline Imóveis rurais cadastrados no CAR & 271.745 & 38,6 \\
\hline Assentamentos de Reforma Agrária & 170.163 & 24,2 \\
\hline Quilombolas & 536 & 0,1 \\
\hline Áreas devolutas e não cadastradas & 177.451 & 25,2 \\
\hline \multicolumn{3}{|l|}{ ÁREAS PROTEGIDAS } \\
\hline Unidades de Conservação & 42.917 & 6,1 \\
\hline Terras Indígenas & 24.125 & 3,4 \\
\hline RDS e RESEX & 16.717 & 2,4 \\
\hline Áreas Militares & 78 & 0,0 \\
\hline TOTAL & 703.732 & 100,0 \\
\hline
\end{tabular}

Fonte: INPE (2019).

O mundo rural reuniu $88 \%$ (619.895 ha) das áreas desmatadas em 28.882 polígonos. Os $12 \%$ restantes ( 83.837 ha) ocorreram em áreas protegidas. Mesmo numa hipótese maximalista, de que cada desmatamento individual foi realizado por um produtor rural diferente, isso envolveria menos de $3 \%$ dos cerca de 1.000 .000 de produtores rurais e unidades de produção do bioma Amazônia. Ou ainda, 4\% dos estabelecimentos agropecuários registrados pelo IBGE em 2017.

II.4 Dinâmica do desmatamento nos últimos 10 anos

A análise dos polígonos anuais de desmatamento entre 2009 e 2018 no bioma Amazônia, por geoprocessamento, revelou uma situação relativamente estável: cerca de 30.000 áreas desmatadas por ano com ligeira tendência no aumento do tamanho médio dos polígonos e das áreas desmatadas nos últimos anos (Tab. 7). 
Tabela 7 - Áreas desmatadas no bioma Amazônia entre 2009 e 2018

\begin{tabular}{cccccc}
\hline \multirow{2}{*}{ Ano } & \multirow{2}{*}{$\begin{array}{c}\text { Quantidade de } \\
\text { polígonos }\end{array}$} & Área Total & $\begin{array}{c}\text { Média por } \\
\text { polígono }\end{array}$ & Mín. & Máx. \\
\cline { 4 - 6 } $\mathbf{2 0 0 9}$ & 32.976 & 576.948 & 17,0 & 6,0 & $2.043,0$ \\
\hline $\mathbf{2 0 1 0}$ & 36.995 & 572.905 & 15,0 & 6,0 & $1.768,0$ \\
\hline $\mathbf{2 0 1 1}$ & 32.664 & 523.024 & 16,0 & 6,0 & $1.326,0$ \\
\hline $\mathbf{2 0 1 2}$ & 22.342 & 403.950 & 18,0 & 6,0 & $1.448,0$ \\
\hline $\mathbf{2 0 1 3}$ & 25.871 & 503.801 & 19,0 & 6,0 & $2.684,0$ \\
\hline $\mathbf{2 0 1 4}$ & 25.389 & 478.143 & 19,0 & 6,0 & $2.364,0$ \\
\hline $\mathbf{2 0 1 5}$ & 26.268 & 584.357 & 22,0 & 6,0 & $4.662,0$ \\
\hline $\mathbf{2 0 1 6}$ & 33.656 & 700.882 & 22,0 & 6,7 & $4.091,4$ \\
\hline $\mathbf{2 0 1 7}$ & 31.104 & 668.179 & 21,5 & 6,1 & $1.453,7$ \\
\hline $\mathbf{2 0 1 8}$ & 32.658 & 703.732 & 21,5 & 6,3 & $5.377,2$ \\
\hline MÉDIA & $\mathbf{2 9 . 9 9 2}$ & $\mathbf{5 7 1 . 5 9 2}$ & $\mathbf{1 9 , 1}$ & $\mathbf{6 , 1}$ & $\mathbf{2 . 7 2 1 , 7}$ \\
\hline
\end{tabular}

Fonte: INPE (2019).

\section{Discussão e Conclusões}

\subsection{Dos temas e dos métodos}

Diante do perene desafio de conhecer o universo de produtores, unidades e áreas de produção, a equipe da Embrapa Territorial percebeu, em 2018, a oportunidade criada por duas iniciativas públicas independentes: os dados geocodificados dos imóveis rurais do Cadastro Ambiental Rural (CAR) e as coordenadas geográficas dos estabelecimentos agropecuários recenseados pelo IBGE em 2017.

Os métodos desenvolvidos e os procedimentos executados foram possíveis graças à convergência de ciências exatas, biológicas e humanas na estruturação do Sistema de Inteligência Territorial Estratégica do Bioma Amazônia, capaz de tratar grandes conjuntos de dados geocodificados sociais e econômicos. As informações geradas estão abertas à consulta e servirão para novas pesquisas da equipe e de outros atores da comunidade acadêmica.

\subsection{Dos produtores rurais no bioma Amazônia}

Mais de um milhão de produtores, unidades e áreas de produção foram identificadas em bases territoriais. Estes resultados trazem uma compreensão adicional, inédita e quantificada da territorialidade das unidades de produção e dos produtores rurais, em particular dos pequenos agricultores, em cada município e estado no bioma Amazônia, realidade subestimada no tema do desenvolvimento regional. A invisibilidade da pequena agricultura (NUGENT, 1993) é cada vez maior. As análises socioeconômicas declinaram face ao crescimento da temática ambiental na Amazônia. Diante da insuficiência de informações e trabalhos de pesquisa vinculados à realidade amazônica, como definir políticas públicas adequadas aos desafios de seu mundo rural (BUAINAIN et al., 2014)? 
À população estatística teórica, objeto desta pesquisa, correspondeu um amálgama heteróclito de mais de um milhão de produtores rurais e áreas de produção. E esse mapeamento ainda não foi exaustivo. Ele resulta de três subpopulações: a dos estabelecimentos agropecuários do IBGE coincidentes territorialmente com os imóveis rurais do CAR, a dos estabelecimentos agropecuários do IBGE não correspondentes a imóveis rurais cadastrados no CAR e a dos imóveis do CAR aparentemente não visitados por recenseadores do IBGE.

A primeira subpopulação de 396.488 estabelecimentos agropecuários do IBGE, coincidentes territorialmente com os imóveis rurais do CAR está mapeada e é inequívoca. Ela está nas bases de dados do CAR e do IBGE. Estudos posteriores analisarão seus padrões de repartição territorial nos estados e seus vínculos com os processos mais avançados de regularização fundiária na Amazônia.

A segunda subpopulação é composta por 282.108 estabelecimentos agropecuários do IBGE não cadastrados no CAR. Ela demonstra o esforço do IBGE em atingir pessoas isoladas e áreas remotas. A repartição territorial dessa subpopulação e os trajetos geocodificados dos recenseadores ilustram sua ocorrência ao longo de rios, igarapés e áreas de baixa densidade populacional e econômica. Em parte, essa subpopulação é constituída por apicultores, pescadores e extrativistas, cuja atividade independe de uma fração de terra. Dificilmente se inscreverão no CAR.

A terceira subpopulação é a de 330.128 imóveis rurais cadastrados no CAR, aparentemente não visitados por recenseadores do IBGE. É uma parcela significativa de produtores e áreas rurais. Eles se "movimentaram" em direção ao Poder Público e identificaram seus imóveis no CAR, atendendo às exigências do Código Florestal. Por que essa disjunção com os dados do IBGE?

Parte das explicações possíveis é de ordem operacional: dificuldades de acesso; produtores ausentes ou vivendo em áreas urbanas; mais de 3.000 estabelecimentos sem coordenadas geográficas; áreas com conflitos agrários agudos; cadastros para assegurar a posse em terras devolutas, sem presença, salvo alguma atividade pecuária ou extrativista; imóveis cadastrados com pouca materialidade no campo e diversas situações vicariantes.

Outra explicação, talvez a principal, é de natureza quase epistemológica: a distância entre métodos e meios disponíveis em cada campo científico para captar a realidade amazônica e a complexidade de seu mundo rural. Formas complexas de acesso, controle, ocupação, uso, transmissão e transferência das terras e seus recursos no espaço rural amazônico, entrelaçam no tecido social as dimensões agrícolas, agrárias e rurais. Por exemplo, em reservas extrativistas, os produtores além de explorar borracha, açaí ou castanhas, também criam gado ao longo do ano como pecuaristas, inseridos de forma complexa nas cadeias de pecuária. E cultivam a terra. Parte da família obtém e vive de rendas extragrícolas, trabalha em áreas urbanas, graças à mobilidade que motocicletas trouxeram ao mundo rural.

Várias unidades de produção vegetal e animal, de residência, de parentesco, de renda, de consumo, de gestão e decisão, de uso e ocupação da terra se entrelaçam, em harmonia e conflito, sob um pesado manto de legislações e exigências trabalhistas, ambientais, tributárias etc. Os conceitos de imóvel rural e de estabelecimento agropecuário captam apenas parte dessa realidade. Sua compreensão exige a humildade de deixar de lado esquemas pré-concebidos para 
buscar e formular novas hipóteses e testá-las com números, mapas e fatos. E persistência. Com a publicação completa dos resultados do Censo Agropecuário de 2017, será possível investigar melhor esse fenômeno. E prosseguir nessa pesquisa. Sic itur ad astra.

\subsection{Das relações entre produtores rurais e desmatamento}

Há mais de 30 anos, o Brasil detecta, mapeia e quantifica as áreas desmatadas por corte raso no bioma Amazônia. A análise por geoprocessamento dos polígonos anuais de 10 anos de desmatamento (2009 a 2018) revelou uma situação relativamente estável: cerca de 30.000 áreas desmatadas por ano.

Das áreas e do número total de polígonos de desmatamentos cerca de $12 \%$ ocorrem fora do mundo rural, em áreas de parques nacionais, terras indígenas etc. Dos 27.000 polígonos restantes, menos de $40 \%$ ocorreram em imóveis cadastrados no CAR. Mesmo numa hipótese maximalista, em que cada desmatamento individual foi realizado por um produtor rural diferente, isso envolveria menos de 27.000 atores ou menos de $3 \%$ dos mais de 1.000 .000 de produtores rurais e unidades de produção existentes no bioma. Esses dados serão refinados no futuro.

Desmatar não significa ilegalidade. Os produtores rurais têm o limitado direito de explorar $20 \%$ dos imóveis, como rege o Código Florestal. Muitos ainda não atingiram esse valor. Uma situação de legitimidade, distante do anátema reiterado por muitos contra os agricultores amazônicos. E vale relembrar um pouco da história do desenvolvimento regional. Em cerca de 50 anos, os governos estabeleceram 2.405 assentamentos agrários no bioma Amazônia e instalaram 521.000 famílias. A maioria segue sem título de propriedade de seu pequeno lote. Como obter financiamento sem regularização fundiária? Como solicitar autorização de desmatar para plantar mandioca? Mesmo quem solicita, respeitando o Código Florestal, não recebe. Multados, muitos produtores perdem acesso ao PRONAF. Estão no fundo do poço. O mundo urbano exige que saiam do buraco sozinhos, de forma "sustentável" e cumpram seu dever de "guardiões das florestas".

Se estivessem nas cidades, os pequenos produtores fariam parte da economia informal, como cabeleireiros, quituteiras, entregadores, vendedores etc. Há décadas, políticas públicas urbanas buscam reduzir a informalidade de prestadores de serviço, facilitando os impostos e a criação de microempresas. O mundo rural deve ser apoiado e não criminalizado por discursos simplistas, em que até setores exportadores e capitalizados do agronegócio tem se envolvido.

Os pequenos produtores fazem um enorme esforço de profissionalização, aumentam sua competitividade com inovações tecnológicas (BROWN; JEPSON; PRICE, 2004), abastecem o mercado regional de mais de 500 cidades. Produzem o que comem (FANZO, 2017). Precisam de mais (e melhor) assistência técnica, extensão, associações, cooperativas, regularização fundiária, acesso a informação, novas tecnologias e circuitos de comercialização. Eles querem ser atores e autores do desenvolvimento regional na Amazônia. Faz tempo. 


\section{Referências}

BROWN, J.C., JEPSON, W.; PRICE, K.P. Expansion of Mechanized Agriculture and Land-Cover Change in Southern Rondônia, Brazil. Journal of Latin American Geography, n. 3, p. 96-102, 2004. Disponível em: <https://muse.jhu.edu/article/177858/summary>. Acesso em: 22 out. 2019.

BUAINAIN, A. M. et al. O mundo rural no Brasil do século 21: a formação de um novo padrão agrário e agrícola. Brasília: Embrapa, 2014. 1182 p. Disponível em:

<https://www3.eco.unicamp.br/nea/images/arquivos/O_MUNDO_RURAL_2014.pdf>. Acesso em: 01 jun. 2019.

ENVIRONMENTAL SYSTEMS RESEARCH INSTITUTE - ESRI. ArcGIS 10.7. Disponível em: <http://www.esri.com/software/arcgis/arcgis-for-desktop>. Acesso em: 22out. 2019a.

. ArcGIS File Geodatabases. Disponível em:

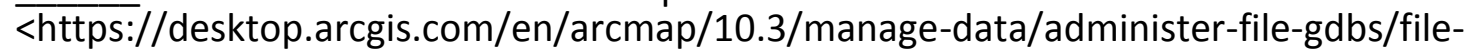
geodatabases.htm>. Acesso em: 22 out. 2019b.

FANZO, J. From big to small: the significance of smallholder farms in the global food system. The Lancet Planetary Health. Volume 1, ISSUE 1, Pe15-e16, April 01, 2017. Disponível em $<$ https://www.thelancet.com/journals/lanplh/article/PIIS2542-5196\%2817\%29300116/fulltext>. Acesso em 22 out. 2019.

GOOGLE. Google Earth Pro. Disponível em:

<https://www.google.com/work/mapsearth/products/earthpro.html>. Acesso em: 22 out. 2019.

INSTITUTO BRASILEIRO DE GEOGRAFIA E ESTATÍSTICA - IBGE. Censo Agropecuário 2017. Disponível em: <https://www.ibge.gov.br/estatisticas/economicas/agricultura-epecuaria/21814-2017-censo-agropecuario.html?=\&t=o-que-e>. Acesso em: 22 out. 2019a.

. Censo Agropecuário 2017: download das coordenadas geográficas. Disponível em: $\overline{<h t t p s: / / w w w . i b g e . g o v . b r / e s t a t i s t i c a s / e c o n o m i c a s / a g r i c u l t u r a-e-p e c u a r i a / 21814-2017-c e n s o-~}$ agropecuario.html?edicao=23751\&t=downloads $>$. Acesso em: 22 out. 2019b.

. Estrutura Territorial. 2014. Disponível em:

<https://www.ibge.gov.br/geociencias/organizacao-do-territorio/estrutura-territorial.html>. Acesso em: 22 out. 2019c.

. Projeto SIRGAS: Sistema de Referência Geocêntrico para as Américas. 2010. Disponível em: <hhttps://www.ibge.gov.br/geociencias/informacoes-sobre-posicionamento-

geodesico/sirgas/16691-projeto-mudanca-do-referencial-geodesico-pmrg.html?=\&t=o-que-e>. Acesso em: 22 out. 2019 d.

INFRAESTRUTURA NACIONAL DE DADOS ESPACIAIS - INDE. Infraestrutura Nacional de Dados Espaciais. Disponível em: <https://inde.gov.br/>. Acesso em: 22 out. 2019.

INSTITUTO DO PATRIMÔNIO HISTÓRICO E ARTÍSTICO NACIONAL - IPHAN. Geoglifos do Acre. Disponível em: <http://portal.iphan.gov.br/pagina/detalhes/822>. Acesso em: 22 out. 2019.

INSTITUTO NACIONAL DE PESQUISAS ESPACIAIS - INPE. Projeto PRODES: Monitoramento do Desmatamento da Floresta Amazônica Brasileira por Satélite. Disponível em:

<http://www.obt.inpe.br/OBT/assuntos/programas/amazonia/prodes>. Acesso em: 22 out. 2019.

Conceitos de Cartografia. 2011. Disponível em:

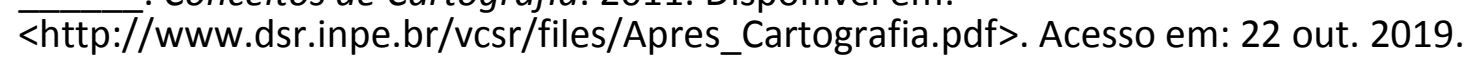


MIRANDA, E. E. de et al. Sistema de Inteligência Territorial Estratégica do Bioma Amazônia. Embrapa Territorial. 2019. Disponível em

<http://www.cnpm.embrapa.br/projetos/siteamazonia>. Acesso em: 12 out. 2019.

MIRANDA, E. E. de et al. Number, maps and facts: Agriculture leads environmental preservation. Proceedings of the First International Conference on Agro Big Data and Decision Support Systems in Agriculture September 27-29 2017, Montevideo, Uruguay. Disponível em <https://www.embrapa.br/territorial/busca-de-publicacoes/-/publicacao/1078639/numbermaps-and-facts-agriculture-leads-environmental-preservation>. Acesso em: 22 out. 2019.

MIRANDA, E. E. de. Quando o Amazonas corria para o Pacífico. Uma história desconhecida da Amazônia. 2. ed. Petrópolis: Vozes, 2007.

NEUMANN, P. S.; VIVIEN, D. O Problema da não definição da Unidade Econômica Básica na Agricultura. Disponível em: <http://www.sober.org.br/palestra/5/1180.pdf>. Acesso em: 22 out. 2019.

NUGENT, S. Amazonian Caboclo Society: An Essay on Invisibility and Peasant Economy. Berg Publishers, London. 1993.

SERVIÇO FLORESTAL BRASILEIRO - SFB. Cadastro Ambiental Rural. Disponível em: <http://www.car.gov.br/publico/imoveis/index>. Acesso em: 22 out. 2019. 